\title{
Comparison of the Cutaneous Wound Healing of Ovariectomized Mouse at 12 Weeks with That of SHAM and Estrogen-Administered Mice
}

\author{
Kanae Mukai, ${ }^{1}$ Yuriko Miyasaka, ${ }^{1}$ Kana Takata, ${ }^{1}$ Tamae Urai, ${ }^{1}$ Yukari Nakajima, \\ Emi Komatsu, ${ }^{1}$ Junko Sugama, ${ }^{2}$ and Toshio Nakatani ${ }^{2}$ \\ ${ }^{1}$ Department of Clinical Nursing, Graduate Course of Nursing Science, Division of Health Sciences, Graduate School of Medical, \\ Pharmaceutical and Health Sciences, Kanazawa University, 5-11-80 Kodatsuno, Kanazawa 920-0942, Japan \\ ${ }^{2}$ Faculty of Health Sciences, Institute of Medical, Pharmaceutical and Health Sciences, Kanazawa University, \\ 5-11-80 Kodatsuno, Kanazawa 920-0942, Japan
}

Correspondence should be addressed to Toshio Nakatani; nakatosi@staff.kanazawa-u.ac.jp

Received 14 February 2014; Accepted 4 June 2014; Published 7 July 2014

Academic Editor: Elisabetta Baldi

Copyright (C) 2014 Kanae Mukai et al. This is an open access article distributed under the Creative Commons Attribution License, which permits unrestricted use, distribution, and reproduction in any medium, provided the original work is properly cited.

\begin{abstract}
The aim of this experiment was to investigate the effect of $17 \beta$-estradiol on cutaneous wound healing in 12 -week ovariectomized (OVX) female mice. Eight-week-old female mice were divided into three groups: administration of $17 \beta$-estradiol after OVX (OVX $+17 \beta$-estradiol), OVX, and sham (SHAM). Four weeks after surgery, the mice received two full-thickness cutaneous wounds. 17 $\beta$ Estradiol at $0.01 \mathrm{~g} /$ day was administered on the backs of mice in the OVX $+17 \beta$-estradiol group every day. Plasma $17 \beta$-estradiol level in the OVX $+17 \beta$-estradiol group was thus significantly higher than in the SHAM and OVX groups, but there was no significant difference between SHAM and OVX groups. The ratio of wound area was not significantly different among the three groups. However, the period required to reach a ratio of wound area of 0.15 in the OVX $+17 \beta$-estradiol group was significantly shorter than in the SHAM and OVX groups. These results indicate that cutaneous wound healing in young OVX mice was promoted by the administration of $17 \beta$-estradiol compared with that in SHAM and OVX mice without such administration, but there was no difference between the latter two groups that did not differ in $17 \beta$-estradiol level.
\end{abstract}

\section{Introduction}

Cutaneous wound healing is a complex tightly orchestrated response to injury, carefully regulated at temporal and spatial levels [1]. With advanced age in humans and rodents, this series of events becomes disrupted and healing is delayed [24].

Recently, it has come to light that this series of events is also disrupted by estrogenic sex steroids in the healing of acute cutaneous wounds [5]. In young female rodents, that had undergone ovariectomy (OVX), cutaneous wound healing was delayed by systemic reduced estrogen compared with that in SHAM [6-15], whereas exogenous estrogen treatment reversed this delay by decreasing wound area [6-15], reducing local production of the inflammatory cells neutrophils or macrophages [7-11, 13], as well as the proinflammatory cytokine TNF- $\alpha$ [7-11], and promoting reepithelialization $[8,10-13]$ and collagen deposition [6]. Therefore, previous research suggested that estrogen promotes cutaneous wound healing in OVX female rodents by several effects.

However, previous work evaluating the effect of estrogen used only 8- to 10-week-old female mice, and, to the best of our knowledge, no research using aged female mice has been presented. Therefore, we investigated the effect of $17 \beta$ estradiol on cutaneous wound healing using 24-week OVX female mice [16]. We clarified that exogenous and continuous $17 \beta$-estradiol administration promoted cutaneous wound healing in 24-week OVX female mice by reducing wound area, shortening the inflammatory response, and promoting wound contraction more than in mice with OVX alone. In addition, no parameters in our previous research showed significant differences between SHAM and OVX 
mice. Moreover, although previous research reported that plasma $17 \beta$-estradiol level in OVX rodents was lower than that in SHAM rodents $[17,18]$, our previous study showed that plasma $17 \beta$-estradiol levels between SHAM and OVX mice were not significantly different [16]. Therefore, the aim of this research was to clarify whether the wound healing of young female mice that undergo OVX at 8 weeks old and are wounded at 12 weeks old differs from that of SHAM mice.

\section{Materials and Methods}

2.1. Animals. Forty-two C57BL/6 female mice aged 7 weeks (Sankyo Lab Service Co., Tokyo, Japan) were used in this experiment. They were caged individually in an airconditioned room at $25 \pm 2.0^{\circ} \mathrm{C}$ with light from 08:45 to 20:45 hours, and water and chow were given freely. All animal experiments conducted in this study were reviewed and approved by Kanazawa University Animal Experiment Committee and carried out in accordance with the Guidelines for the Care and Use of Laboratory Animals of Kanazawa University, Japan (AP-091208).

2.2. Wounding. The mice were bred for 1 week. At this time, they were anesthetized by intraperitoneal (IP) injection of pentobarbital sodium $(0.05 \mathrm{mg} / \mathrm{g}$ weight $)$, and the dorsum was shaved. Then, they were subjected to sham surgery (SHAM) or ovariectomy (OVX) according to the OECD guidelines [19]. Four weeks later, they were divided into three groups: SHAM group, OVX group, and OVX $+17 \beta$-estradiol group. Then, under anesthesia with shaving, two circular full-thickness skin wounds ( $4 \mathrm{~mm}$ in diameter) including the panniculus carnosus muscle on both sides of the dorsum of the mouse were made with a Kai sterile disposable biopsy punch (Kai Industries Co. Ltd., Gifu, Japan). In the SHAM and OVX groups, the wounds were covered with hydrocolloid dressings (Tegaderm; $3 \mathrm{M}$ Health Care, Tokyo, Japan) to maintain a moist environment, and then the mouse was wrapped with sticky bandages (Meshpore Tape; Nichiban, Tokyo, Japan), which were changed every day. In the OVX $+17 \beta$-estradiol group, wounds received the same treatment. However, after wound treatment, they were also treated with $0.01 \mathrm{~g}$ of $17 \beta$-estradiol gel (L'estrogel $0.06 \%$; Bayer Yakuhin, Osaka, Japan). It was placed on wrap film using a $1 \mathrm{~mL}$ syringe and applied to the back skin avoiding the wounds every day. We performed a preliminary experiment on the dose of $17 \beta$-estradiol. In this experiment, $0.01 \mathrm{~g}, 0.02 \mathrm{~g}$, and $0.05 \mathrm{~g}$ of $17 \beta$-estradiol gel were administered to each OVX mice and wound area was measured for 15 days. In terms of the results, wound area did not significantly differ among the doses. In addition, plasma $17 \beta$-estradiol level in the mice with OVX and administration of $0.01 \mathrm{~g}$ of $17 \beta$-estradiol was significantly greater than that of the mice with OVX alone. Therefore, we selected $17 \beta$-estradiol administered at a dose of $0.01 \mathrm{~g}$ in our experiment.

2.3. Macroscopic Observation. The day when wounds were made was designated as day 0 , and the process of wound healing was observed from days 0 to 21 . Wound edges were traced on polypropylene sheets and photographs were taken every day. The traces on the sheets were captured with a scanner onto a personal computer using Adobe Photoshop Elements 7.0 (Adobe System Inc., Tokyo, Japan), and the areas of wounds were calculated using the image analysis software Scion Image Beta 4.02 (Scion Corporation, Frederick, MD, USA).

2.4. Plasma $17 \beta$-Estradiol Assay. The mice were euthanized by pentobarbital sodium IP injection on day 20. Plasma was prepared from each mouse's blood isolated through cardiac puncture and frozen until the time of assay. Plasma $17 \beta$-estradiol level was determined by radioimmunoassay (RIA). This was outsourced to the manufacturer of this assay (Mitsubishi Chemical Medience Corporation, Tokyo, Japan).

2.5. Vaginal Smears. Vaginal smears were carried out for 7 days before wounding in the SHAM and OVX groups. In the OVX $+17 \beta$-estradiol group, they were performed for 7 days before and after wounding. A cotton wool tip was moistened by dipping into saline. The tip of the swab stick was inserted carefully into the mouse's vagina with rotation of the swab. Then, the tip was rolled on a glass slide. The samples were fixed in $100 \%$ alcohol and stained with hematoxylin and eosin (H-E). Images were imported onto a computer using a digital microscopic camera (DP2-BSW Olympus, Japan).

2.6. Histological Procedure and Microscopic Observation. The mice were euthanized by the injection of a lethal dose of pentobarbital sodium IP on days 7, 11, and 15 after wounding. The wound and the surrounding intact skin were harvested. They were stapled onto polypropylene sheets to prevent overcontraction and fixed in zinc fixative (BD Pharmingen, Tokyo, Japan) for 24 hours. Then, the wound and surrounding intact skin were bisected at the wound center. The samples were dehydrated in an alcohol series, cleaned in xylene, and embedded in paraffin to prepare $5 \mu \mathrm{m}$ serial paraffin sections. The sections of $5 \mu \mathrm{m}$ thickness were stained with $\mathrm{H}$-E. Images were imported onto a computer using a digital microscopic camera (DP2-BSW Olympus, Japan).

2.7. Statistical Analysis. Data are expressed as mean $\pm \mathrm{SD}$, analyzed using JMP 8.0.1 (SAS, USA). ANOVA or TukeyKramer multiple comparison test was performed. Differences were considered significant at $P<0.05$.

\section{Results}

3.1. Plasma $17 \beta$-Estradiol Levels. We confirmed that the ovaries had been removed successfully in the OVX and OVX + $17 \beta$-estradiol groups. All of the mice had plasma $17 \beta$-estradiol levels under $10 \mathrm{pg} / \mathrm{mL}$ in the SHAM group, while 12/13 mice had levels under $10 \mathrm{pg} / \mathrm{mL}$ and the other mouse had a level of $17 \mathrm{pg} / \mathrm{mL}$ in the OVX group. On the other hand, in the OVX + $17 \beta$-estradiol group, only $3 / 13$ mice had plasma $17 \beta$-estradiol levels under $10 \mathrm{pg} / \mathrm{mL}$, while the remaining 10 mice with levels over $10 \mathrm{pg} / \mathrm{mL}$ had a mean of $17.2 \pm 5.8 \mathrm{pg} / \mathrm{mL}$. Plasma $17 \beta$-estradiol levels in the OVX $+17 \beta$-estradiol group were 


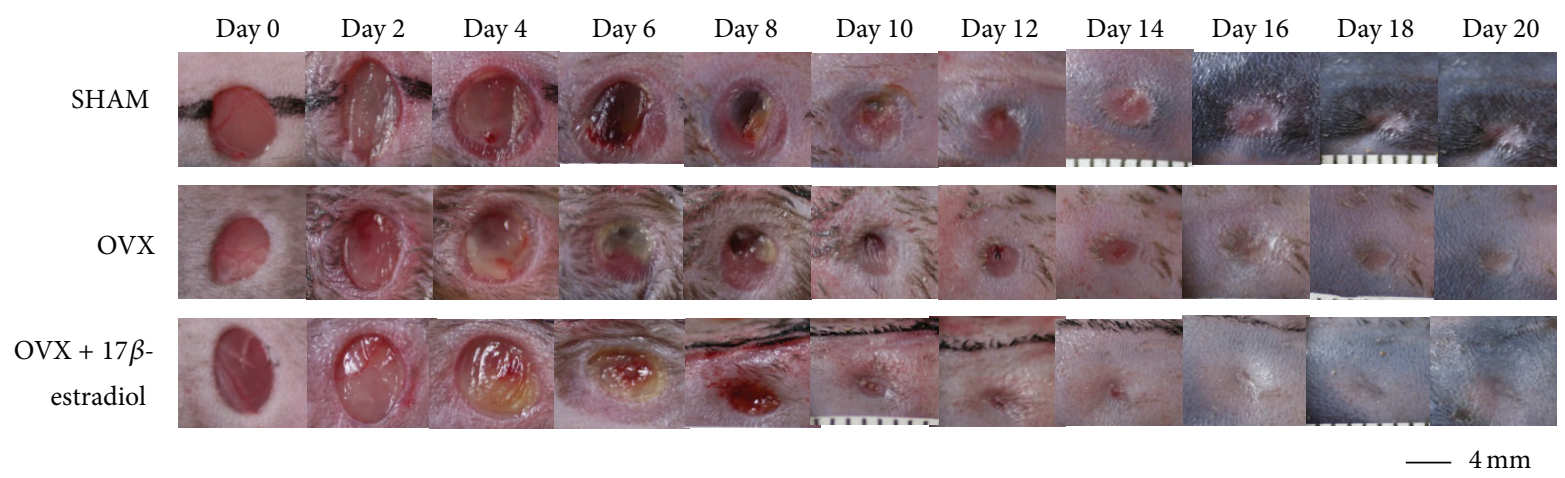

(a)

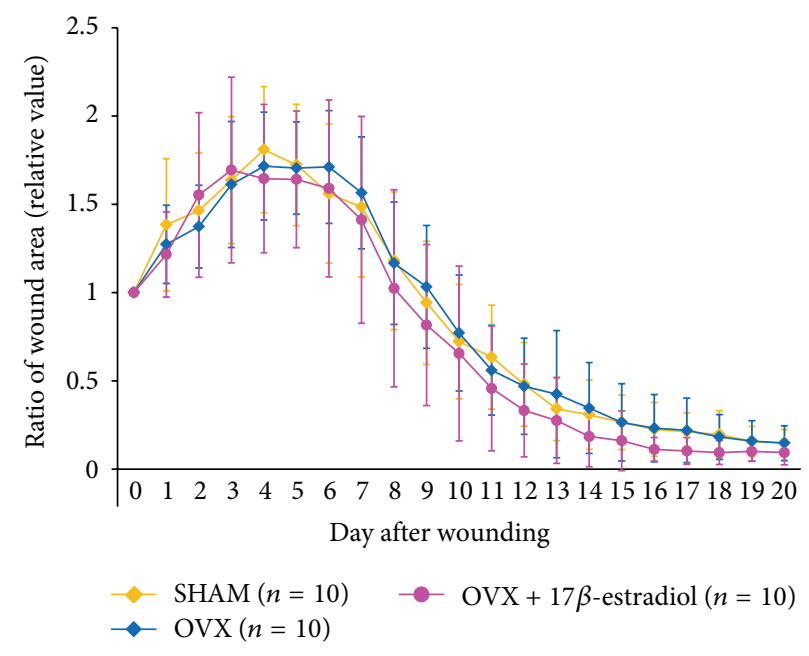

(b)

FIGURE 1: Macroscopic wound healing. (a) Four mm diameter wounds were inflicted and healing was recorded by photography. Bar, 4 mm. (b) Ratios of wound areas to the initial area on day 0 are shown on line graphs for each day. There were no significant differences among the three groups. Values are expressed as mean $\pm \mathrm{SD}, n=10$ for each group.

significantly higher than those in the SHAM and OVX groups $(P<0.0001$ and 0.0002 , resp.). However, there were no significant differences between the SHAM and OVX groups.

3.2. Vaginal Smears. In the SHAM group, four different figures, proestrus, estrus, metestrus, and diestrus, were observed for 7 days before wounding. In the OVX group, diestrus with leukocytes was maintained for 7 days before wounding. In the OVX $+17 \beta$-estradiol group, estrus with cornified squamous epithelial cells was maintained for 7 days after wounding.

3.3. Wound Area. In the SHAM group, wound areas rapidly increased for 4 days and then peaked $(1.81 \pm 0.36$, ratio of wound area to initial wound area on day 4 after wounding). They subsequently decreased rapidly until day 13 after wounding $(0.34 \pm 0.18$, ratio of wound area to initial wound area on day 13 after wounding), after which they decreased slowly until day 20 after wounding $(0.15 \pm 0.07$, ratio of wound area to initial wound area on day 20 after wounding). In the OVX group, wound areas rapidly increased for 4 days and peaked at days 4 to 6 after wounding $(1.71 \pm 0.30$ to $1.71 \pm 0.31$, ratio of wound area to initial wound area on days 4 to 6 after wounding). Then, they decreased rapidly until day 15 after wounding $(0.27 \pm 0.21$, ratio of wound area to initial wound area on day 15 after wounding), after which they decreased slowly until day 20 after wounding $(0.15 \pm 0.09$, ratio of wound area to initial wound area on day 20 after wounding). On the other hand, in the OVX $+17 \beta$-estradiol group, wound area rapidly increased for only 3 days and then peaked $(1.72 \pm 0.31$, ratio of wound area to initial wound area on day 3 after wounding), after which it decreased slowly until day 6 after wounding. Then, it decreased rapidly until day 14 after wounding $(0.18 \pm 0.17$, ratio of wound area to initial wound area on day 14 after wounding) and slowly again until day 16 after wounding $(0.10 \pm 0.07$, ratio of wound area to initial wound area on day 16 after wounding), after which the wound area was almost unchanged until day 20 after wounding $(0.09 \pm 0.07$, ratio of wound area to initial wound area on day 20 after wounding).

There were no significant differences among the three groups on days $0-20$. However, the mean ratio of wound area 
in the OVX $+17 \beta$-estradiol group was smaller throughout the whole period, except for days $0-4$ (Figure 1(b)).

3.4. Period Required to Reach Ratio of Wound Area of 0.15. When wounds healed and formed a scar, the mean ratio of the wound area relative to the original size reached 0.15 . For example, wounds on day 18 in the SHAM and OVX groups, and on day 14 or day 16 in the OVX $+17 \beta$-estradiol group, showed a scar (Figure 1(a)). We calculated the period required to reach a ratio of wound area of 0.15 for each group. These periods were $18.0 \pm 1.83$ days in the SHAM group, $19.1 \pm 3.0$ days in the OVX group, and $14.0 \pm 2.86$ days in the $\mathrm{OVX}+17 \beta$-estradiol group (Figure 2 ), with that of the OVX + $17 \beta$-estradiol group being significantly shorter than those of the other two groups ( $P=0.0005$ for both). However, there was no significant difference between the SHAM and OVX groups (Figure 2).

3.5. Microscopic Findings. On day 7, after wounding, wound width was almost the same among the three groups. On the other hand, progression of reepithelialization in the OVX + $17 \beta$-estradiol group seemed to occur faster than in the SHAM and OVX groups (Figures 3(a), 3(c), and 3(e)).

On day 11, after wounding, wound width, that is, the width of the granulation tissue of the center of the wound, in the OVX $+17 \beta$-estradiol group seemed to be shorter than that in the SHAM and OVX groups. New epithelium completely covered the wound surface in the three groups.

On day 15, after wounding, the widths of wounds in all groups were shorter than those on day 11 .

\section{Discussion}

In this study, vaginal smears in the OVX $+17 \beta$-estradiol group showed that estrus with cornified squamous epithelial cells was maintained for 7 days after wounding and plasma $17 \beta$-estradiol levels in the OVX $+17 \beta$-estradiol group were significantly higher than those in the SHAM and OVX groups. However, in the SHAM and OVX groups, plasma $17 \beta$ estradiol levels were almost always under $10 \mathrm{pg} / \mathrm{mL}$. These results show that $17 \beta$-estradiol administered percutaneously was sufficiently absorbed. On the other hand, although estrus cycle was not observed in the OVX group, but in the SHAM group, plasma $17 \beta$-estradiol levels were not significantly different between these two groups. Moran et al. reported that the plasma $17 \beta$-estradiol level of OVX mice was under $10 \mathrm{pg} / \mathrm{mL}$ [18]. Nelson et al. reported that this level was around $20-30 \mathrm{pg} / \mathrm{mL}$ in the proestrus state [20], while Walmer et al. reported that it increased and peaked in the proestrus state [21]. However, Haisenleder et al. reported that plasma $17 \beta$-estradiol levels in SHAM and OVX groups were almost always under $10 \mathrm{pg} / \mathrm{mL}$ [22] and our previous study reported that plasma $17 \beta$-estradiol levels showed no significant differences between SHAM and OVX mice [16]. Comparing these findings with our study, it cannot necessarily be said that the level of $17 \beta$-estradiol in SHAM mice is always higher than that in OVX mice. We are planning to examine whether the level

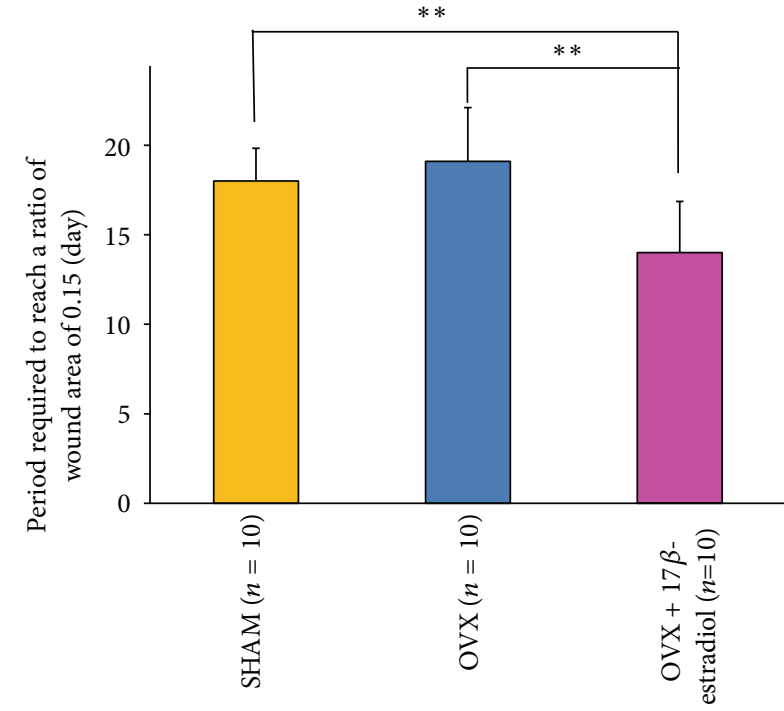

Figure 2: Period required to reach a ratio of wound area of 0.15 . The period required to reach this ratio in the OVX $+17 \beta$-estradiol group was significantly shorter than that in the SHAM and OVX groups. However, there were no significant differences between the SHAM and OVX groups. Values are expressed as mean $\pm \mathrm{SD}, n=10$ for each group, ANOVA, Tukey-Kramer. ${ }^{* *} P<0.01$ : versus the OVX + $17 \beta$-estradiol group.

of $17 \beta$-estradiol shows a difference depending on age in future work.

In this study, although the ratio of wound area relative to the original size in the OVX $+17 \beta$-estradiol group was not significantly different from those in the SHAM and OVX groups, the periods required to reach a ratio of wound area of 0.15 in the OVX $+17 \beta$-estradiol group were significantly shorter than those in the SHAM and OVX groups. Previous research reported that exogenous estrogen treatment promoted cutaneous wound healing in 8-10-week OVX female mice by decreasing wound area [6-15]. Our previous study also reported that exogenous and continuous $17 \beta$-estradiol administration promoted cutaneous wound healing in 24week OVX female mice by decreasing wound area, and plasma $17 \beta$-estradiol level in OVX $+17 \beta$-estradiol mice was significantly higher than that in OVX mice [16]. In the present work, plasma $17 \beta$-estradiol level in the OVX $+17 \beta$ estradiol group was also significantly higher than those in the SHAM and OVX groups. These findings indicate that cutaneous wound healing in young mice was promoted when a high level of $17 \beta$-estradiol was administered in OVX mice, compared with those in SHAM mice and mice with OVX alone.

On the other hand, the ratio of wound area was not significantly different between the SHAM and OVX groups on days $0-20$ and the transition of the ratio of wound area was almost the same in these two groups. Many previous studies reported that wound area in 8-10-week OVX mice was significantly larger than that in SHAM mice [6-15], although none of these previous studies reported the reproductive status. Calvin et al. reported that the ratio of wound area was 


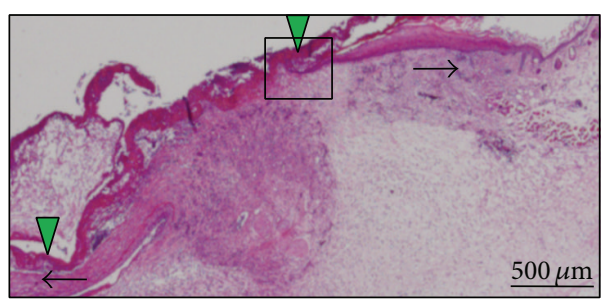

(a)

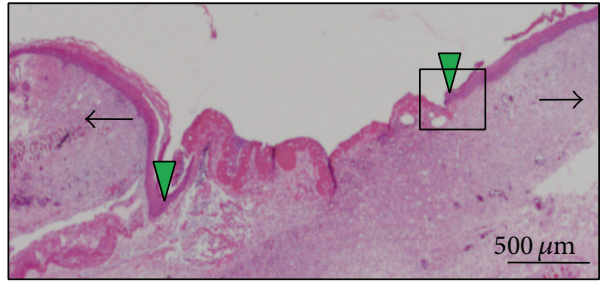

(c)

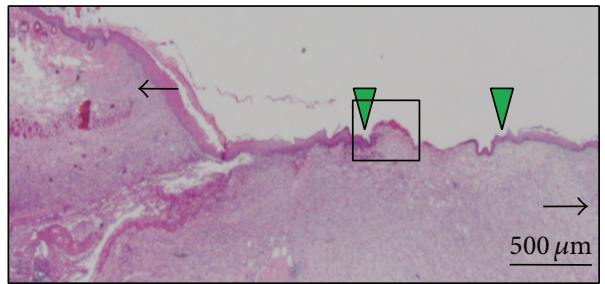

(e)

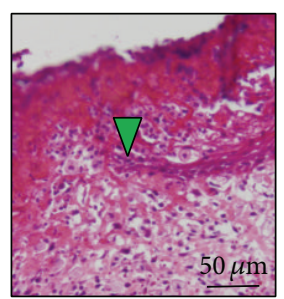

(b)

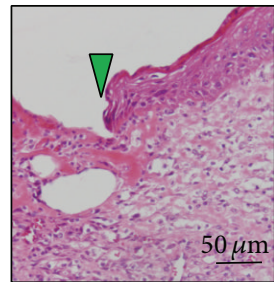

(d)

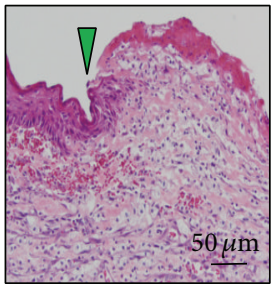

(f)

FIGURE 3: Hematoxylin and eosin staining of sections on day 7. (a) Section of the SHAM group. Bar, $500 \mu \mathrm{m}$. (b) Enlargement of the square in (a). Bar, $50 \mu \mathrm{m}$. (c) Section of the OVX group. Bar, $500 \mu \mathrm{m}$. (d) Enlargement of the square in (c). Bar, $50 \mu \mathrm{m}$. (e) Section of the $17 \beta$-estradiol group. Bar, $500 \mu \mathrm{m}$. (f) Enlargement of the square in (e). Bar, $50 \mu \mathrm{m}$. Arrows indicate wound edges and arrowheads indicate the tip of new epithelium.

not significantly different between SHAM and OVX rodents, when using 9-week female Wistar rats [23]. We estimated from a graph in this previous report that the plasma $17 \beta$ estradiol level in the OVX rats was $28 \mathrm{pmol} / \mathrm{L}(7.63 \mathrm{pg} / \mathrm{mL})$ and $50 \mathrm{pmol} / \mathrm{L}(13.6 \mathrm{pg} / \mathrm{mL})$ in SHAM rats. Moreover, our previous study reported that the ratio of wound area and plasma $17 \beta$-estradiol level were not significantly different between SHAM and OVX mice at 24 weeks of age [16]. In the present study, plasma $17 \beta$-estradiol level was also not significantly different between SHAM and OVX groups. Therefore, it is estimated that cutaneous wound healing in young mice showed no difference between SHAM and OVX mice when the level of $17 \beta$-estradiol was almost the same. That is, it is thought that the model of ovariectomy carried out on a young female mouse does not necessarily directly reflect the status of a menopausal woman. Therefore, we plan to investigate the effect of estrogen on cutaneous wound healing and its mechanism by using mouse models at an advanced age.

\section{Conclusions}

Our study showed that cutaneous wound healing in young mice was promoted by administration of a high level of $17 \beta-$ estradiol in OVX mice compared with the levels in SHAM mice and mice with OVX alone, but cutaneous wound healing showed no difference between these latter two groups that had similar levels of $17 \beta$-estradiol although previous research reported that cutaneous wound healing in OVX mice was delayed compared with that in SHAM mice.

\section{Conflict of Interests}

The authors declare that there is no conflict of interests regarding the publication of this paper.

\section{Authors' Contribution}

Kanae Mukai and Yuriko Miyasaka contributed equally to this work.

\section{Acknowledgment}

Part of this work was supported by JSPS KAKENHI (Grant no. 25293430 to Toshio Nakatani).

\section{References}

[1] T. J. Shaw and P. Martin, "Wound repair at a glance," Journal of Cell Science, vol. 122, no. 18, pp. 3209-3213, 2009. 
[2] G. S. Ashcroft, M. A. Horan, and M. W. J. Ferguson, "Aging alters the inflammatory and endothelial cell adhesion molecule profiles during human cutaneous wound healing," Laboratory Investigation, vol. 78, no. 1, pp. 47-58, 1998.

[3] S. Herrick, G. Ashcroft, G. Ireland, M. Horan, C. McCollum, and M. Ferguson, "Up-regulation of elastase in acute wounds of healthy aged humans and chronic venous leg ulcers are associated with matrix degradation," Laboratory Investigation, vol. 77, no. 3, pp. 281-288, 1997.

[4] G. S. Ashcroft, M. A. Horan, S. E. Herrick, R. W. Tarnuzzer, G. S. Schultz, and M. W. J. Ferguson, "Age-related differences in the temporal and spatial regulation of matrix metalloproteinases (MMPs) in normal skin and acute cutaneous wounds of healthy humans," Cell and Tissue Research, vol. 290, no. 3, pp. 581-591, 1997.

[5] G. S. Ashcroft, T. Greenwell-Wild, M. A. Horan, S. M. Wahl, and M. W. J. Ferguson, "Topical estrogen accelerates cutaneous wound healing in aged humans associated with an altered inflammatory response," The American Journal of Pathology, vol. 155, no. 4, pp. 1137-1146, 1999.

[6] G. S. Ashcroft, J. Dodsworth, E. van Boxtel et al., "Estrogen accelerates cutaneous wound healing associated with an increase in TGF- $\beta 1$ levels," Nature Medicine, vol. 3, no. 11, pp. 1209-1215, 1997.

[7] G. S. Ashcroft, S. J. Mills, K. Lei et al., "Estrogen modulates cutaneous wound healing by downregulating macrophage migration inhibitory factor," The Journal of Clinical Investigation, vol. 111, no. 9, pp. 1309-1318, 2003.

[8] E. Emmerson, L. Campbell, G. S. Ashcroft, and M. J. Hardman, "The phytoestrogen genistein promotes wound healing by multiple independent mechanisms," Molecular and Cellular Endocrinology, vol. 321, no. 2, pp. 184-193, 2010.

[9] M. J. Hardman, E. Emmerson, L. Campbell, and G. S. Ashcroft, "Selective estrogen receptor modulators accelerate cutaneous wound healing in ovariectomized female mice," Endocrinology, vol. 149, no. 2, pp. 551-557, 2008.

[10] C. E. Routley and G. S. Ashcroft, "Effect of estrogen and progesterone on macrophage activation during wound healing," Wound Repair and Regeneration, vol. 17, no. 1, pp. 42-50, 2009.

[11] M. Brufani, F. Ceccacci, L. Filocamo et al., "Novel locally active estrogens accelerate cutaneous wound healing. A preliminary study," Molecular Pharmaceutics, vol. 6, no. 2, pp. 543-556, 2009.

[12] E. Emmerson, L. Campbell, G. S. Ashcroft, and M. J. Hardman, "Unique and synergistic roles for $17 \beta$-estradiol and macrophage migration inhibitory factor during cutaneous wound closure are cell type specific," Endocrinology, vol. 150, no. 6, pp. 2749-2757, 2009.

[13] L. Campbell, E. Emmerson, F. Davies et al., "Estrogen promotes cutaneous wound healing via estrogen receptor $\beta$ independent of its antiinflammatory activities," Journal of Experimental Medicine, vol. 207, no. 9, pp. 1825-1833, 2010.

[14] S. C. Gilliver, J. P. D. Ruckshanthi, M. J. Hardman, T. Nakayama, and G. S. Ashcroft, "Sex dimorphism in wound healing: the roles of sex steroids and macrophage migration inhibitory factor," Endocrinology, vol. 149, no. 11, pp. 5747-5757, 2008.

[15] E. Emmerson, G. Rando, C. Meda, L. Campbell, A. Maggi, and M. J. Hardman, "Estrogen receptor-mediated signalling in female mice is locally activated in response to wounding," Molecular and Cellular Endocrinology, vol. 375, no. 1-2, pp. 149156, 2013.
[16] K. Mukai, Y. Nakajima, T. Urai et al., "The effect of $17 \beta$ estradiol administration on cutaneous wound healing in 24week ovariectomized female mice," Journal of Hormones, vol. 2014, Article ID 234632, 8 pages, 2014.

[17] S. Belisle, D. Bellabarba, and J. G. Lehoux, "On the presence of nonfunctional uterine estrogen receptors in middle-aged and old C57BL/6J mice," Endocrinology, vol. 116, no. 1, pp. 148-153, 1985.

[18] A. M. Moran, S. A. Nelson, R. M. Landisch, G. L. Warren, and D. A. Lowe, "Estradiol replacement reverses ovariectomy-induced muscle contractile and myosin dysfunction in mature female mice," Journal of Applied Physiology, vol. 102, no. 4, pp. 13871393, 2007.

[19] OECD, "Uterotrophic bioassay in rodents: a short-termscreening test for oestrogenic properties," in OECD Guideline for the Testing of Chemicals, no. 440, OECD, 2007.

[20] J. F. Nelson, L. S. Felicio, H. H. Osterburg, and C. E. Finch, "Altered profiles of estradiol and progesterone associated with prolonged estrous cycles and persistent vaginal cornification in aging C57BL/6J mice," Biology of Reproduction, vol. 24, no. 4, pp. 784-794, 1981.

[21] D. K. Walmer, M. A. Wrona, C. L. Hughes, and K. G. Nelson, "Lactoferrin expression in the mouse reproductive tract during the natural estrous cycle: correlation with circulating estradiol and progesterone," Endocrinology, vol. 131, no. 3, pp. 1458-1466, 1992.

[22] D. J. Haisenleder, A. H. Schoenfelder, E. S. Marcinko, L. M. Geddis, and J. C. Marshall, "Estimation of estradiol in mouse serum samples: evaluation of commercial estradiol immunoassays," Endocrinology, vol. 152, no. 11, pp. 4443-4447, 2011.

[23] M. Calvin, M. Dyson, J. Rymer, and S. R. Young, "The effects of ovarian hormone deficiency on wound contraction in a rat model," British Journal of Obstetrics and Gynaecology, vol. 105, no. 2, pp. 223-227, 1998. 


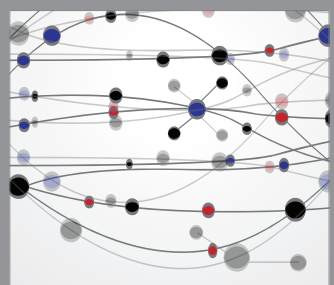

The Scientific World Journal
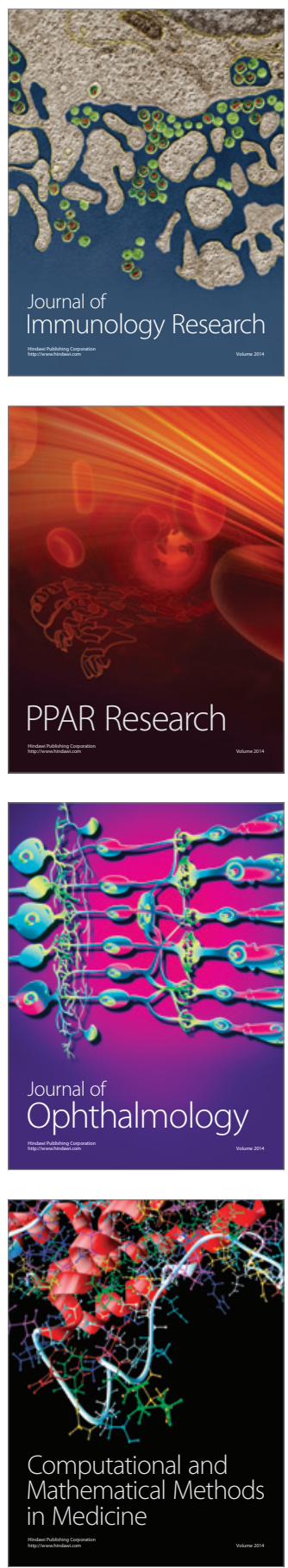

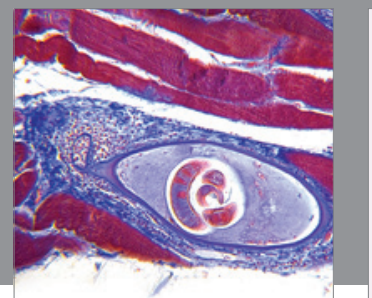

Gastroenterology

Research and Practice
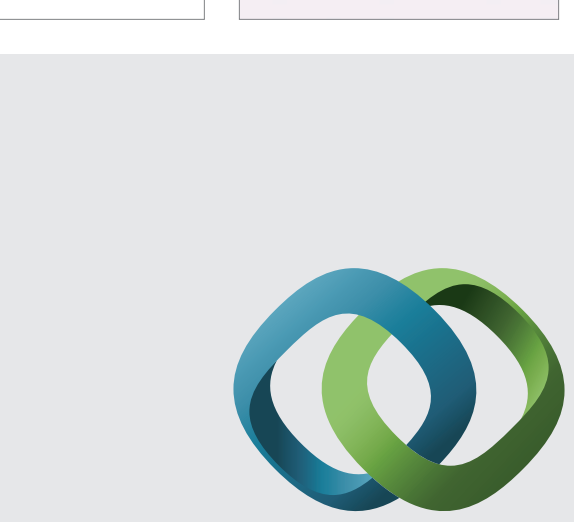

\section{Hindawi}

Submit your manuscripts at

http://www.hindawi.com
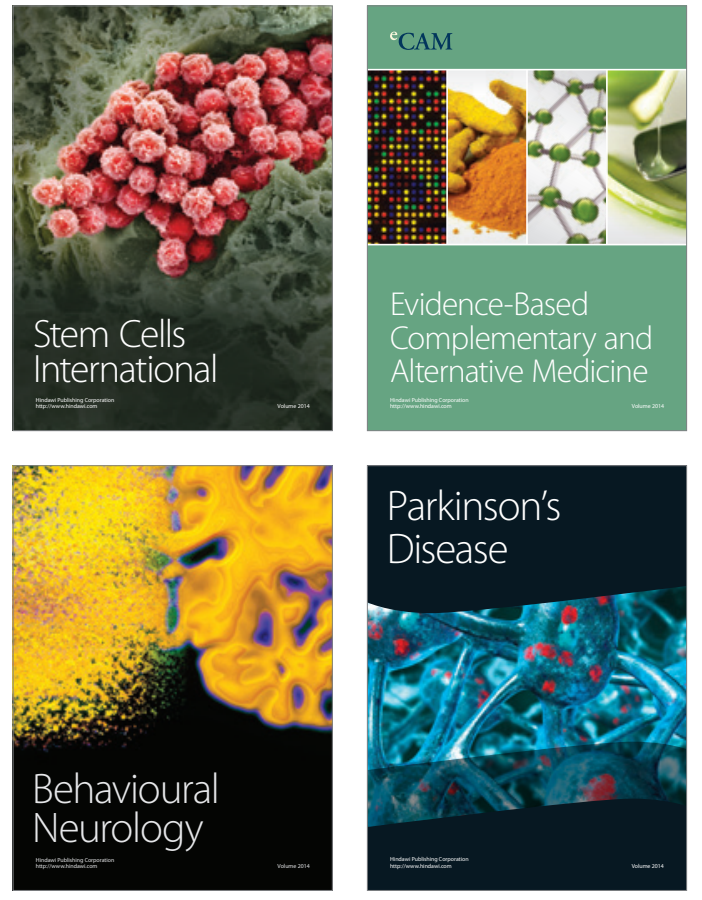
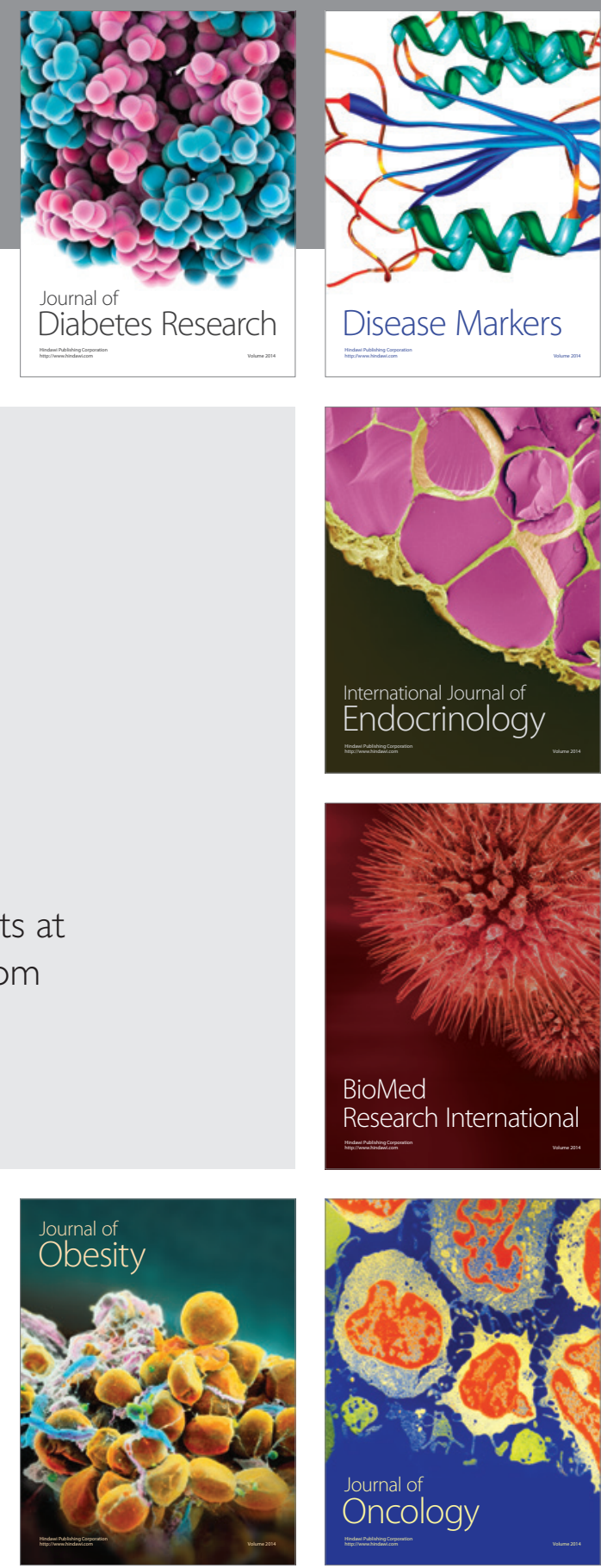

Disease Markers
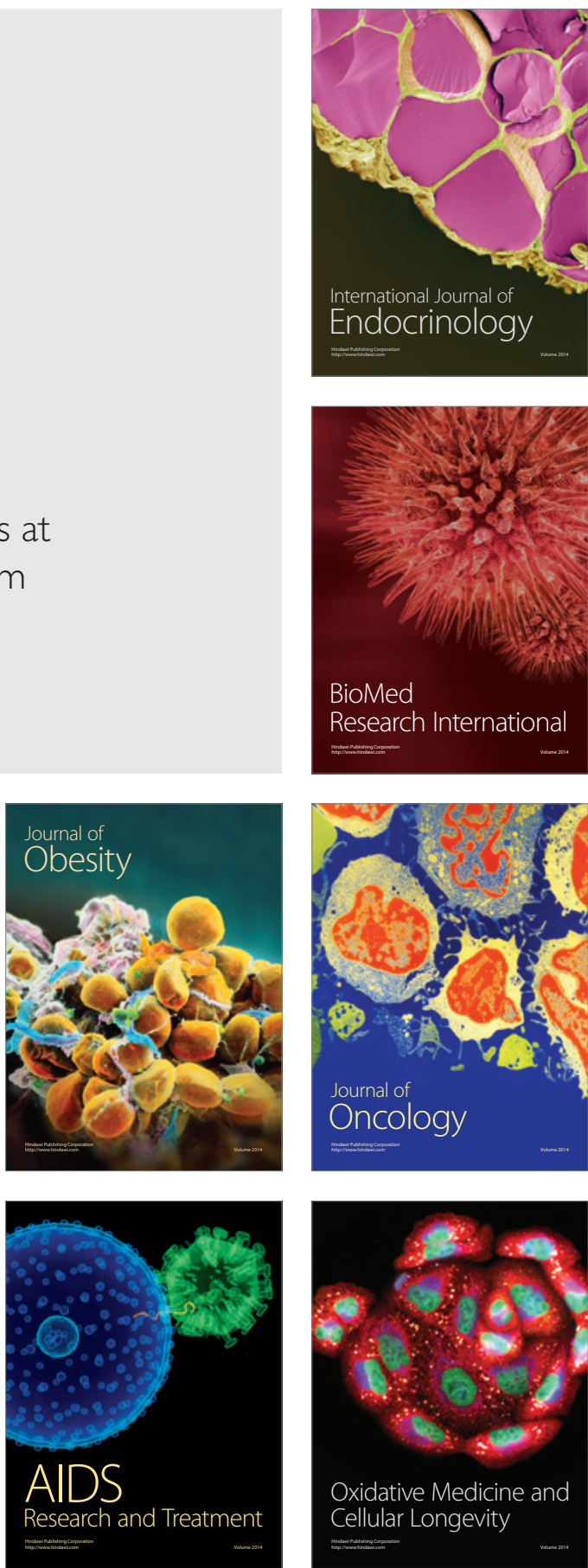